\title{
REGULATION OF EPIDERMAL PROLIFERATION AND DIFFERENTIATION IN PSORIASIS
}

\author{
JOHN J. VOORHEES
}

Psoriasis is a genetic disease with an environmental component. The importance of the genetic versus the environmental com. ponent varies considerably from patient to patient. Nonetheless, a considerable amount of research indicates that psoriasis is apparently a multifactorial genetic disease (1). In psoriasis patients the frequency of HL-A 13 and HL-A 17 cell surface antigens is elevated fourfold (2). This information does little to suggest fruitful avenues of research which will lead to a molecular understanding of the essence of this disease.

It is necessary to therefore choose an area of research in psoriasis which is technically feasible and likely to have pathophysiological importance. We have chosen the epidermis. Stimulated epidermal cell proliferation is a major feature of psoriasis. The disease would probably not exist as we know it, if the epidermis were not a major component. The vascular compartment or dermal signals to the epidermis may be more "primary" than the epidermal disorder. However, the epidermis with difficulty can be sampled and the specimens obtained for biochemical analysis are reasonably free of dermal and vascular contamination. The vessels, dermis and other potential candidates can not be adequately

By Invitation: Presented as the Special Lecuture of the Japanese Dermatological Association, Yonago City, Japan, August 28, 1977.

Supported in part by Program Project Grant \#2 P01 AM 15740-06.

Professor and Chairman of the Department of Dermatology, University of Michigan Medical School, Ann Arbor, Michigan 48109 U.S.A. sampled. To obtain sufficient tissue of either type would require a surgical technique which would produce serious scarring and the procured tissue (vessels and dermis) would be unacceptably heterogenous. From heterogenous tissue comes uninterpretable data. It is for these reasons that our research has focused on epidermal regulation in psoriasis.

In this type of research sequential biopsies of psoriatic epidermis are generally not feasible. The amount of tissue needed for most biochemical techniques and the numbers of patients it is necessary to study due to biological variation make sequential biopsies almost impossible. Therefore, one can not usually decide what is primary or secondary. Until this type of sequential technology is available, research on psoriasis will not advance rapidly. However, until then one can circumvent this serious drawback by studying those aspects of the molecular pathophysiology of psoriasis which are hypothetically amenable to pharmacological modulation. Using this philosophical approach one is not concerned about what is primary or secondary, if the correction of a pathophysiological event normalizes the lesion. An important corollary to our research strategy is that in the initiation and/or maintenance of a lesion, certain, but not all molecular events, whether they are primary or secondary, are critical.

We have termed such events "critical molecular variables" in psoriatic epidermal pathophysiology. In this approach the key ingredient is to make the best educated guesses 
as to which of several thousand events are critical. Today it is my great honor to be here in Yonago to address the Japanese Dermatological Association. My lecture will discuss and explain these "critical variables" which we have studied. There are four such areas which I will consider sequentially: 1) the epidermal cell surface; 2) cyclic nucleotides; 3) arachidonic acid-prostaglandin cascade; 4) polyamines.

\section{THE CELL SURFACE}

The cell surface acts as a switchboard to receive incoming signals (hormonal and environmental stimuli) and to coordinate the cyclic nucleotide and arachidonic acid systems. The cell surface is composed of the plasma membranes, specialized external macromolecules (glycoproteins and glycolipids), and structures on the inner face of the membrane to which the microtubule-microfilament (MTMF) system is attached (3).

In psoriatic lesions the cell surface as visualized by electron microscopy is markedly reduced in thickness (4). The area of reduced thickness is external to the plasma unit membrane and is the putative binding region of cell surface hormones. Intuitively, it would seem that if cell surface defects in psoriasis are sufficiently gross as to be detected by microscopy, that serious defects in hormone binding and cell-cell communication may exist. DNA synthesis in cultured cells can be regulated by the addition of membranes (5). Also, cell surface membrane recognition factors regulate cyclic AMP and cyclic GMP levels in reaggregating sponge cells (6). Perhaps in psoriatic lesions the misregulated cyclic nucleotide systems are secondary to reduced cell surface hormone binding or reduced quantities of macromolecular cell surface recognition factors. However, in cultured cells cyclic AMP regulates the formation of the cell surface $(7,8)$. A delicate balance appears to exist between the regulation of the cyclic AMP system by the cell surface and the regulation of the cell surface by cyclic AMP.

Defective cell surfaces are also associated with changes in membrane fluidity. The amount of cholesterol relative to phospholipid is one determinant of membrane fluidity. As the cholesterol/phospholipid ratio increases, membrane fluidity decreases (9). Since the free cholesterol content of lesional psoriasis is high, membrane fluidity should be decreased (10). Changes in membrane-lipid composition of this kind have been reported to alter the activity of membrane bound enzymes such as adenylate cyclase (9). Therefore, an alteration in cell surface glycolipids and glycoproteins and in plasma membrane fluidity could have major influences on the communication of the cell surface to the nucleus via cyclic nucleotides.

Psoriasis is said to be a multifactorial genetic disease (1). The frequency of the cell surface gene products HL-A 13 and HL-A 17 is increased three to four-fold (11). Whether these HL-A abnormalities are genetic markers or participants in the pathophysiology of the disease is unknown. However, the $\mathrm{H}-2$ gene complex of the mouse is analogous to the HL-A gene complex in man. In mice the $\mathrm{H}-2$ genotype is one regulator of the liver cyclic AMP level (12). The increased frequency of HL-A 13 and HL-A 17 cell surface components in psoriasis might frustrate normal cell surface regulation of the cyclic AMP system.

The MT-MF network is associated with the cell surface and is thought to relay growth regulatory information from the cell surface to the nucleus. Microtubules are composed of tubulin and microfilaments of actin (13). Wanger and Sundquist (14) have reported an accumulation of actin in psoriatic lesional epithelial cells suggesting the possiblity of an alteration of the MT-MF system as an important event in the deranged growth control 
of psoriasis. Puck (13) has shown that for a normal organized array of MT-MF one must have normal or increased levels of cyclic AMP. In psoriasis the cyclic AMP function is reduced and it might be this reduction which alters the MT-MF array, thus rendering the array more prominent when viewed by immunofluorescent antibody techniques.

Clearly the cell surface of involved areas is abnormal. Whether this abnormality is primary or secondary, it is likely to be important in lesional pathophysiology for reasons discussed above. The unusual frequency of the HL-A cell surface phenotype in psoriasis suggests that the psoriatic cell surface membrane may be a substantial aspect of the predisposition to the disease. Cell surface biochemistry and biophysics are at an advanced state of technology. Unfortunately many of these methods require large quantities of relatively undisturbed membranes. The isolation of epidermal membranes of any quantity, and sufficiently intact to be useable, has not yet been achieved.

Perhaps this membrane technology could be used to compare psoriatic with normal membranes from blood lymphocytes. From lymhocytes adequate membrane preparation can be achieved. The use of lymphocytes may be successful if the psoriatic genotype is expressed in the lymphocyte and in the lymphocyte membrane specifically. If so, hormone receptor binding, glycoprotein/glycolipid profiles, and membrane fluidity could be studied in normal subjects in comparison with psoriasis patients. However, it is possible that psoriasis genes are expressed only or predominantly in the skin. If so, the psoriatic skin membrane studies will await a new technology. As mentioned previously, the cell surface and cyclic AMP are a functioning unit with the cell surface serving as a switchboard for incoming stimuli (injury or hormonal etc.).
We must therefore discuss the cyclic AMP system in psoriasis at this point.

\section{THE CYCLIC AMP SYSTEM}

The characteristic features of involved psoriatic epidermis are increased basal cell proliferation $(15,16)$, increased glycogen content in the center of the hyperplastic rete peg (17), and reduced morphological differentiation in the outer one third of lesional epidermis (18). In 1971 we proposed that these abnormalities might be due to a defective cyclic AMP system (19). Metabolic regulation mediated by cyclic AMP depends not on cyclic AMP per se, but on the differentiated state of the cell in which the regulation occurs. In various cells and cell layers, cyclic AMP, at least in many cases, is a promoter of the expression of differentiated properties (20). Thus a defective epidermal cyclic AMP system could be expected to produce one kind of abnormality in one epidermal layer (i.e., in creased proliferation) and yet a different abnormality in a higher layer.

This theory was based on several earlier observations. Bullough and Laurence (21) showed that epidermal cell division was inhibited by epinephrine. Johnson and Pastan (22) reported that cyclic AMP elevating agents stimulated morphological differentiation in cultured fibroblasts. Sutherland and Rall (23) had previously demonstrated that cyclic AMP was the mediator of beta adrenergic epinephrine induced phosphorylase activation and glycogen breakdown. Thus, it seemed that decreased function of the cyclic AMP system might result in proliferation, decreased differentiation and glycogen storage within the lesion and that stimulation of the cAMP system might normalize these changes.

This concept was supported by studies showing a statistically significant 43 percent decrease in lesional cyclic AMP content in 
comparison with uninvolved or normal epidermis (24). Subsequently, using a different assay we demonstrated a lesser but statistically significant $36 \%$ decrease in the cyclic AMP content of lesional epidermis (25). These lesional cyclic AMP reductions have not been confirmed by others. Härkönen et al. (26) reported increased lesional cyclic AMP levels and Yoshikawa et al. (27) detected no change. Since quite different psoriatic tissue preparations have been used by each research group, it is not surprising that different data have been generated. Considering the technical difficulties in procuring biopsies from psoriatic patients and the large number of patients already studied, it seems unlikely that further study of the cyclic AMP level will be productive.

Also the cyclic AMP level per se is but one possible defect in the cyclic AMP system. This system is composed of several sequential steps from the epidermal cell surface receptor to the as yet unstudied putative protein substrates in the epidermis which are phosphorylated by cyclic AMP dependent protein kinases (28). A defect in this system or interference with its function should reduce the extent of cyclic
AMP mediated epidermal protein phosphorylation (Fig. 1). Thus a reduced "cyclic AMP effect" could be produced by interference with one of the several components of the cyclic AMP system. This is a tenable postulate since all evidence to date suggests that the epidermal cyclic AMP system is similar to that of other tissues (28).

As yet no study of cyclic AMP dependent protein phosphorylation in psoriatic epidermis has been reported. However, the functional state of the psoriatic epidermal cell surface receptor-adenylate cyclase complex has been studied. Yoshikawa et al. (29) have reported that involved psoriatic epidermis contains less cyclic AMP than uninvolved epidermis after both have been stimulated by beta catacholamine. Also involved areas produce less cyclic AMP than uninvolved when stimulated by prostaglandin of the $\mathrm{E}$ series (30). In confirmation of these date Mahrle and Orfanos (31) have found reduced cyclic AMP formation in response to isoproterenol stimulation using cytochemical techniques in psoriasis. Thus the capacity of involved psoriatic epidermis to produce cyclic AMP in response to hormonal signals appears to be

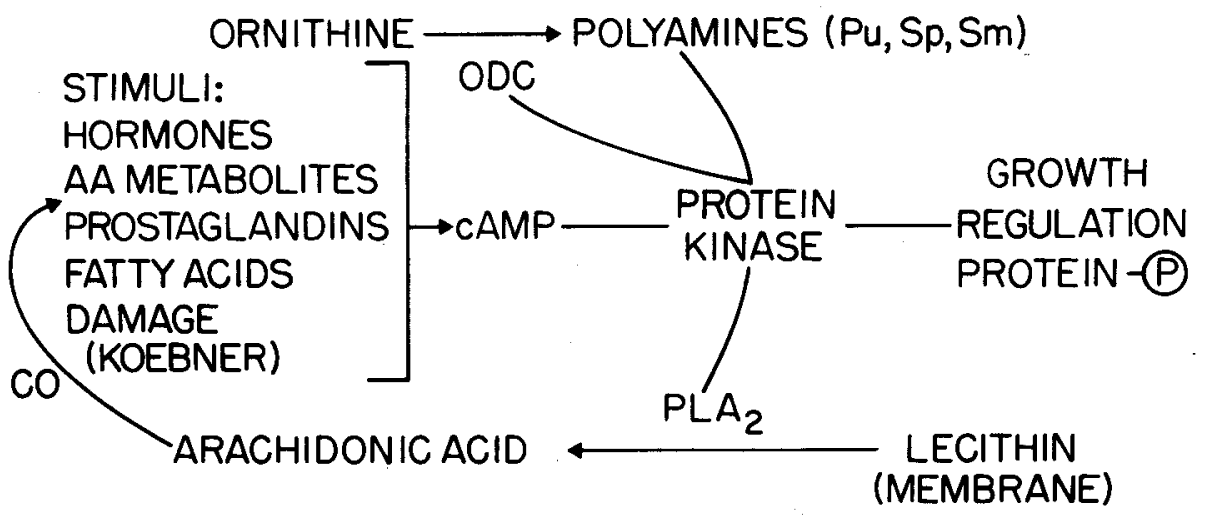

Fig. 1. Hypothetical Interrelationships of Cyclic AMP, Arachidonic Acid and Polyamines in the Regulation of Epidermal Proliferation and Differentiation in Psoriasis. Abbrev: ODC, ornithine decarboxylase; $\mathrm{Pu}$, putrescine; Sp, spermidine; Sm, spermine; AA, arachidonic acid; cAMP, cyclic adenosine $3^{\prime}, 5^{\prime}$ monophosphate; $\mathrm{CO}$, cyclooxygenase; PLA, phospholipase $A_{2}$. 
reduced. It is difficult to see how this reduced cyclic AMP synthetic activity could result in increased lesional cyclic AMP levels as reported by Härkönen et al. (26). However, it is com. patible with either normal or reduced lesional cyclic AMP levels as shown by Yoshikawa et al. (27) and Voorhees et al. (24), respectively.

There are several more recent pieces of information which, although indirect, are compatible with a defective cyclic AMP system in psoriasis. Lithium is a known inhibitor of adenylate cyclase (32). Furthermore, if one incubates psoriatic epidermis in lithium at a concentration found in the blood stream of a lithium controlled manic depressive patient, cyclic AMP formation in response to isoproterenol is markedly inhibited by the lithium (33). Psoriatic patients who develop manic depressive illness have been reported in whom as the mania improves, the psoriatic lesions become resistant to methotrexate and topical steroids (34) and uninvolved areas become involved (35). The possible involvement of inhibited cyclic AMP synthesis in this response of psoriatic patients to lithium must be considered.

A beta adrenergic blocking agent, practolol, formerly available in Europe, and propranolol, another beta blocker, have been reported to precipitate several types of rashes, one of which is psoriasis-like (36). Intracutaneous testing failed to support the possibility that this reaction was the result of type I or type IV hypersensitivity (36). Possibly beta blockers prevent cutaneous beta catecholamines from maintaining a normal epidermal cyclic AMP content. As in the case of lithium, psoriatic patients taking oral practolol were resistant to antipsoriatic therapy and new psoriatic lesions developed.

Subsequently, Wiley and Weinstein (37) injected propranolol into clinically uninvolved psoriatic skin and into the skin of normal subjects. By autoradiography they demonstrated that propranolol produced a 6 -fold increase in the number of proliferating cells in psoriatic epidermis. These data might be explained by a genetically impaired cyclic AMP generating system in psoriatic skin which is further compromised to a. point of malfunction (i.e., increased cell proliferation) by propranolol. In summary, it is interesting that two structurally different agents (i.e., lithium and beta blockers) both inhibit cyclic AMP formation and both promote the formation of new lesions and render existing lesions refractory to both systemic and topical antipsoriasis drugs.

Other molecular observations have been made in lesional psoriatic epithelium which are compatible with a malfunctioning cyclic AMP system. Vassalli et al. (38) demonstrated that plasminogen activator production in cell culture is inhibited by compounds which raise the cellular cyclic AMP level and is inhibited by glucocorticoids. The plasminogen activator activity in lesional epithelium is increased (39). Glucocorticoids are known to markedly im. prove psoriasis and substances which can elevate intracellular cyclic AMP content also improve psoriasis when applied topically (40, 41).

The presence of increased glycogen levels in psoriatic lesions is perhaps of minimal metabolic significance. However, its presence is interesting because when normal or involved psoriatic epidermis is incubated with epinephrine, glycogen breakdown occurs (42). Thus, epidermal glycogen can be regulated by cyclic AMP as can glycogen in other cells. The location of glycogen in the more central areas of lesional epidermis may indicate that cells in that location are experiencing a reduced cyclic AMP signal.

As discussed above, our earliest theory proposed that cyclic AMP in epidermis might 
serve as an antiproliferative compound and a morphogen (19). This theory has been studied by several researchers using epidermal cells in culture. Delescluse et al. (43) demonstrated that elevated cyclic AMP inhibited the proliferation of guinea pig epidermal cells in vitro. Flaxman and Harper (44) later demonstrated that the proliferation of human keratinocytes in culture were markedly inhibited by several compounds which resulted in cyclic AMP elevation. Delescluse et al. (45) reported that epidermal cell differentiation was stimulated in vitro by cyclic AMP additions to the cultures. This observation was extended by Chopra (46) who saw that keratohyalin granule production was stimulated by cyclic AMP added to human epidermal cells in culture.

If the net cyclic AMP effect is decreased in psoriatic lesional epithelium, lesions might improve if stimulated by cyclic AMP. Posternak et al. (47) injected dibutyryl cyclic AMP with and without theophylline directly into psoriatic lesions with modest results. In China (48) cyclic AMP or dibutyryl cyclic AMP was administered intramuscularly or intravenously to psoriatic patients. Of 69 patients so treated the authors concluded that this therapy was effective in 80 percent. Stawiski et al. (40) applied papaverine topically to psoriatic lesions in 45 patients and observed a statistically significant improvement. These investigators (41) then reported that another topical cyclic AMP elevating agent known as Ro 20-1724 produced statistically significant improvement of psoriasis.

Thus the several molecular and clinical lines of evidence presented here suggest that the cyclic AMP system has decreased function in psoriasis. However, the nature of this misregulation is not understood and requires further research. How this research could be approached experimentally can be visualized in Figure 1. Cell surface stimuli may not be properly received by the defective cell surface (4). Iizuka et al. (49) have provided some evidence that the cell surface can not properly receive an incoming beta catecholamine signal but can normally receive other hormonal signals which produce elevated cellular cyclic AMP. Whether this defect is due to generalized in vivo desensitization (50) or very selective desensitization (51) is unknown. Thus, the reduced capacity of lesional epidermis to form cyclic AMP in the presence of isoproterenol could be due to prior in vivo receptor desensitization with a genetically normal membrane beta receptor phenotype. If this is true, the reduced catecholamine sensitivity should be temporary and reversible under definable in vitro conditions. The elevation of lesional cyclic AMP content according to our theory (19) should improve the lesion. Therefore, a key question is whether beta receptor linked cyclic AMP generation specifically can be related to pathophysiology. That is, when the lesional beta receptor is again able to promote the synthesis of cyclic AMP in vivo, does the lesion begin to resolve.

Figure 1 also shows how a defect distal to cyclic AMP formation could produce a functional decrease in the cellular response to cyclic AMP. The binding of cyclic AMP to the receptor subunit of cyclic AMP dependent protein kinase may be impaired. The kinase could be primarily altered by a genetically produced amino acid substitution in an area of the kinase molecule which reduces receptor binding. Reduced binding, depending on its extent, could produce reduced function. Alternatively, the "milieu interieur" (52) of lesional epidermal cells may not and quite likely is not normal. That is to say, the molecular constituents of the intracellular cell fluid within the epidermal cell plasma membranes may not be optimal. Enzymic systems in regulatory biology must have a 
normal microenvironment to properly perform their catalytic functions. Thus in Figure 1, cyclic AMP dependent protein kinase and its specific phosphoprotein substrate(s) may be normal but the intracellular enzymic microenvironment may prevent the kinase from providing normal phosphorylation or the protein substrate(s) from accepting phosphorus. Either functional defect distally could produce the same "cyclic AMP deficiency state" as could an actual reduction in the cyclic AMP level per se, proximally.

It is apparent from examining Figure 1 that there are several ways by which the necessary cellular cyclic AMP function can be reduced: 1) reduced ability of the cell surface receptors to stimulate adenylate cyclase activity thereby producing reduced cellular cyclic AMP levels; 2) reduced ability of the kinase to carry out the distal functions of the cyclic AMP which was formed in response to hormone binding to the epidermis; 3) reduced ability of the protein substrate for kinase to act as a phosphate acceptor. In all these situations, it makes no difference whether the interference in the cyclic AMP cascade is primary or secondary. The end result is the same-reduced epidermal lesional cyclic AMP function. What does make a difference is whether the reduced cyclic AMP signal is biologically important. Throughout this part of my lecture, I have discussed various data which suggests that cyclic AMP is important. However, all these data (eg., glycogen, lithium, practolol, in vitro cyclic AMP effects, topical application of papaverine and Ro 20-1724, etc.) are indirect and subject to several interpretations.

Evidence must be developed which directly proves that cyclic AMP can modulate epidermal function. If it does, then the potential participation of cyclic AMP in the mismodulated psoriatic epidermis is greater. To this end we have labored over the last three years on the cultivation of mouse epidermal cells in vitro. This endeavor has met with scuccess (53). We are very reproducibly cultivating primary epidermal cells from neonatal mice on plastic dishes without the need for a collagen substrate or 3T3 fibroblasts. Using this system we were quite surprised but delighted to observe that cyclic AMP when added to these cells, causes a several fold increase in their rate of proliferation. Other hormones which also raised intracellular cyclic AMP caused increased proliferation. Other studies showed that in these cells, it was the rise in cyclic AMP that caused the proliferation and not a rise in cyclic GMP (54).

We were surprised by these results in that stimulation rather than inhibition (the expected result) occurred. However, we were pleased because any time one speaks of inhibited proliferation, there is always the question of whether the inhibition is due to the known mechanism of action of the inhibitor or whether the dose response curves were generated by a fundamentally cytotoxic substance. It is most unlikely that any cell system can respond to a cytotoxic agent with stimulated cell proliferation. It is quite likely that cell proliferation induced by cyclic AMP in these cultures is a cyclic AMP specific, noncytotoxic response. Therefore, in these cultures it is likely that physiologically occurring cyclic AMP can modulate proliferation. If one examines the cyclic nucleotide literature, it is apparent that the tissue response to elevated cyclic AMP levels is dependent on the tissue type and the differentiated state of the tissue. It is therefore possible to advance the hypothesis that cyclic AMP may stimulate neonatal mouse epidermis and inhibit adult human epidermis either due to different ages, species or both. To test this hypothesis we are developing similar cultures of human adult 
epidermis. However, the stimulated proliferation in neonatal tissue described above makes it possible to state that cyclic AMP probably does have an important role in epidermal physiology and probably in pathology as well. This is an excellent area for future research and we are currently continuing along these lines. Since cyclic GMP has been implicated in psoriatic pathophysiology, we will discuss cyclic GMP at this point.

\section{THE CYCLIC GMP SYSTEM}

Many investigators agree that cyclic AMP may modulate in vitro cell proliferation. It appears that cyclic AMP may be a significant regulator of proliferation in epidermis as well. However the role of cyclic GMP in the regulation of cellular growth either in vitro or in vivo is unclear. Hadden et al. (55) were the first to discover an association between stimulated lymphocyte proliferation and elevated levels of cellular cyclic GMP. Several proliferative cell systems in which a similar association exists have been recently reviewed by Goldberg and Haddox (56). However, several cell proliferation systems have been described in which the cyclic GMP content either does not rise or in fact, falls when proliferation occurs. Perhaps the best studied situation is that reported by Nesbitt et al. (57). Rapidly dividing transformed cells in culture were found to have a low cyclic GMP content and markedly reduced guanylate cyclase acitivity in comparison with their nontransformed counterparts. The true role of cyclic GMP in the regulation of cell division is unknown.

In psoriasis Voorhees et al. (58) reported an increased lesional cyclic GMP content. More recently, Marcelo et al. (59) found elevated cyclic GMP levels in lesions of a larger group of psoriatic subjects confirming the earlier report. Perhaps this elevation of cyclic GMP in psoriatic lesions is significantly associated with the increased lesional cell proliferation. Presently, the elevated cyclic GMP in psoriasis is an interesting observation, the importance of which in psoriatic pathophysiology is yet to be discovered.

From this discussion it seems that misregulat ed cyclic AMP action in psoriasis may well be a fruitful area of future research. Furthermore, the role of cyclic GMP in lesional pathophysiology may be more important than can currently be predicted.

\section{THE ARACHIDONIC AGID-PROSTAGLANDIN SYSTEM}

For this reason we have been interested in studying the regulation of cyclic nucleotide (cyclic AMP and cyclic GMP) synthesis in skin. Agents which raise cyclic AMP in skin are similar to agents which raise cyclic AMP in other organs. One of these compounds is prostaglandin. Prostaglandin is an excellent candidate in the regulation of cyclic AMP formation because a locally acting agent is required. Lesions of psoriasis are in patches with sharp borders and adjacent normal appearing skin. If a circulating hormone were involved in the misregulated cyclic nucleotide metabolism of psoriasis, the disease would be generalized rather than located in patches. Prostaglandins are formed and degraded locally in tissues and cells and do not circulate in a hormonally active state (60).

Prostaglandins are synthesized from arachidonic acid. It is the release of free arachidonic acid from arachidonic acid esterified into cell membrane phospholipids that is the rate limiting reaction in the cascade. The release of arachidonic acid occurs when tissues are injured or are hormonally stimulated (Fig. 2). Released free arachidonic acid is transformed to a substance known as 12 L-hydroxy-5, 8, 10, 14-eicosatetraenoic acid (HETE), cyclic endoperoxides, thromboxane 


\section{PHARMACOLOGICAL BLOCKERS:

XGLUCOCORTICOID
- INDOMETHACIN
LIKE DRUGS
- ETA (TYA)

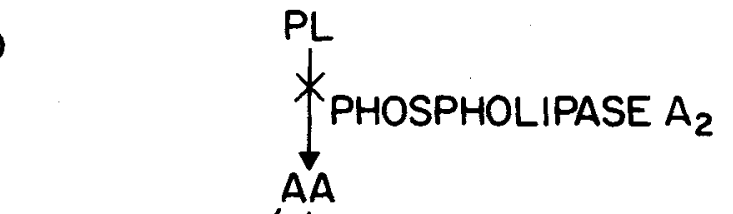

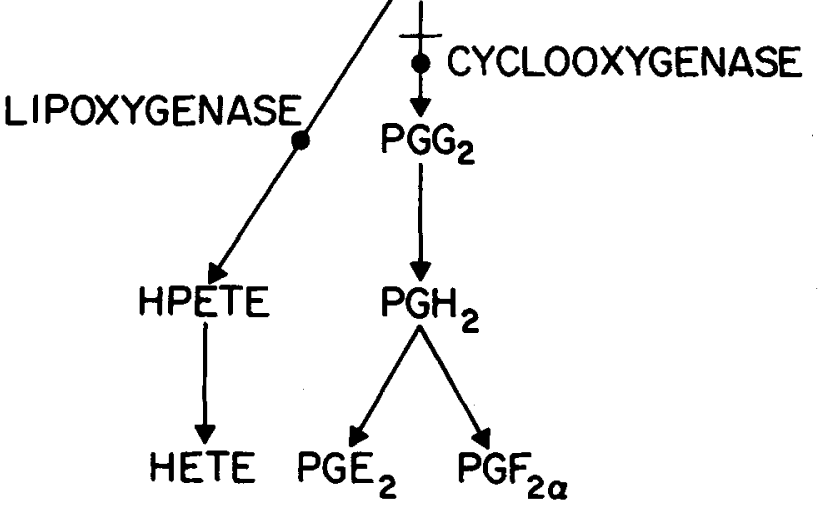

Fig. 2. Arachidonic Acid-Prostaglandin Cascade in Psoriatic Epidermis. The $\mathbf{2 6}$-fold increase in lesional AA content is $95 \%$ inhibited by plastic film occluded glucocorticoid plus cream vehicle. Psoriatic cyclooxygenase is markedly inhibited by indomethacin whereas both lipoxygenase and cyclooxygenase are inhibited by ETA. Arachidonic acid in psoriatic epidermis is transformed into the metabolites seen in this figure. In other tissues different metabolites have been detected such as thromboxane and prostacycline. Such metabolites are not detectable in either psoriatic or normal epidermis. Abbrev: PL, phospholipid; $A A$, arachidonic acid; $\mathrm{PGG}_{2}$ and $\mathrm{PGH}_{2}$, the two prostaglandin cyclic endoperoxides; $\mathrm{PGE}_{2}$, prostaglandin $\mathrm{E}_{2} ; \mathrm{PGF}_{2 \alpha}$ prostaglandin $\mathrm{F}_{2 \alpha} ; \mathrm{HPETE}$, hydroperoxy-HETE; HETE, 12L-hydroxy-5, 8, 10, 14-eicosatetraenoic acid; ETA (TYA), 5, 8, 11, 14-eicosatetraynoic acid.

and the classical prostaglandins, $\mathrm{PGE}_{2}, \mathrm{PGF}_{2 \alpha}$ and $\mathrm{PGD}_{2}(60)$. These various intermediates all can modulate the content of cyclic nucleotides in tissue as reviewed by Voorhees et al. (61).

In an attempt to determine how these metabolites might regulate cyclic nucleotides in psoriasis, it was first necessary to identify these metabolites and their levels in psoriatic tissue. This was done by Hammarström et al. (62) who reported a 26 -fold increase in the content of free arachidonic acid and an 82 -fold increase in HETE levels in involved versus uninvolved epidermis. This was a striking finding since the content of free arachidonic acid in normal tissues is barely detectable and that minimal detectable level is usually thought to have been released by inadvertent tissue manipulation.

Hammarström et al. (62) also detected a 40 and $80 \%$ increase in the lesional levels of $\mathrm{PGE}_{2}$ and $\mathrm{PGF}_{2 \alpha}$, respectively. This minimal increase was unexpected since high arachidonic acid levels in tissue are usually transformed into classical prostaglandins. Thus it appears that in lesional tissue of psoriasis, there is an endogenous inhibition of prostaglandin biosynthesis in vivo. In relation to the large quantity of released arachidonic acid, the lesion may be said to have a relative prostaglandin deficiency. This relative prostaglandin deficiency may be the result of an endogenous inhibitor of prostaglandin biosynthesis 
described by Penneys et al. (63). This inhibitor is dialyzable but is not susceptible to ribonuclease, deoxyribonuclease or proteases.

As previously mentioned, the major disturbance in psoriasis is the large increase in free arachidonic acid (26-fold) which is transformed primarily into HETE. Turner et al. (64) first reported that HETE was chemotactic for polymorphonuclear leukocytes (PMNs). This was confirmed by Goetzl et al. (65) using human PMNs. Psoriatic lesions have considerable numbers of PMNs. It is possible that the high HETE content is an important factor in the chemoattraction of PMNs into the lesion. In fact, Penneys et al. (66) injected arachidonic acid metabolites, one of which was presumably HETE, intradermally into human volunteers. They found that this injection attracted large numbers of PMNs into the injection site suggesting that the endogenous HETE content in psoriasis could indeed be one important chemoattractant.

In psoriasis the release of arachidonic acid and its transformation into HETE may disturb cyclic nucleotide metabolism. Wallach and Pastan (67) showed that arachidonic acid per se stimulated guanylate cyclase activity and thus is a compound which might promote the accumulation of cyclic GMP in tissues. Subsequently, Hidaka and Asano (68) found that the hydroperoxy-form of HETE, which is always formed as arachidonic acid is transformed into HETE, stimulated guanylate cyclase activity.

Unsaturated fatty acids also inhibit adenylate cyclase activity thus preventing the accumulation of cyclic AMP in tissue. Anderson and Jaworski (69) showed that arachidonic acid per se inhibited adenylate cyclase activity. Also lysolecithin not only is a potent activator of guanylate cyclase, but it is a potent inhibitor of adenylate cyclase activity $(69,70)$. Since lysolecithin is formed as arachidonic acid is released in tissues, it is possible that the lysolecithin content of psoriatic lesions is elevated. Lysolecithin is also known to be a potent inhibitor of prostaglandin biosynthesis at concentrations which are physiologically plausible (71). Thus the putative elevation in psoriatic lesional lysolecithin may disturb cyclic nucleotide synthesis and is also a candidate for the dialyzable inhibitor of lesional prostaglandin biosynthesis described by Penneys et al. (63).

Although the levels of lesional prostaglandin $\mathrm{E}_{2}$ and $\mathrm{F}_{2 \alpha}$ reported by Hammarström et al. (62) may represent a relative deficiency, the absolute levels are minimally increased. Since prostaglandin $F_{2 \alpha}$ has been reported to stimulate the formation of cyclic GMP and prostaglandin $E_{2}$ the formation of cyclic AMP, the elevated lesional levels of these two prostaglandins in relation to the lesional cyclic nucleotide content requires comment. In our hands, prostaglandin $\mathrm{F}_{2 \alpha}$ has not been capable of elevating lesional cyclic GMP and only at high $\left(1 \times 10^{-3}\right.$ to $\left.1 \times 10^{-5} \mathrm{M}\right)$ concentrations does prostaglandin $E_{2}$ elevate epidermal cyclic AMP. Also, lesional prostaglandin levels remain elevated for the life of a lesion. It seems quite possible that this would possibly lead to in vivo desensitization of prostaglandin receptors. When this desensitization phenomenon occurs cells could be refractory to prostaglandin induced increases in cyclic nucleotide content (50). In essence, the cells could perform as though the increased prostaglandin content did not exist. Thus the steady state lesional prostaglandin level may bear little relationship to the steady state cyclic nucleotide content. When considering the role of prostaglandins in the regulation of lesional cyclic nucleotide content, it is clearly preferable to consider the role of all the products of arachidonic acid. As discussed above, the various metabolites of arachidonic acid are capable of regulating cyclic nucleotide biosynthesis. In psoriasis 
therefore, it is of interest to know the effect of arachidonic acid per se, HETE and hydroperoxy HETE on cyclic nucleotide synthesis.

Since arachidonic acid levels are markedly increased in psoriasis, we will briefly consider its regulation in other tissues for what value such information may contribute to psoriasis. The rate limiting enzyme in the synthesis (release) of free arachidonic acid from membrane phospholipids is known as phospholipase $A_{2}$ (60). Lapetina et al. (72) and Minkes et al. (73) have shown that in horse and human platelets respectively, cyclic AMP inhibits the release of arachidonic acid presumably by inhibiting the activity of phospholipase $\mathrm{A}_{2}$. Thus in psoriasis by stimulating the sluggish cyclic AMP system, it may be possible to correct the abnormally high release of arachidonic acid. The cyclic nucleotide system and the arachidonic acidprostaglandin cascade appear to be functionally interdependent. The arachidonic acid metabolites switch on cyclic AMP formation which in turn switches off arachidonic acid release. Whether cyclic AMP does in fact inhibit arachidonic acid release in psoriatic lesions is currently under investigation.

\section{THE POLYAMINES}

Putrescine, spermidine and spermine are three substances which are collectively called polyamines. The rate limiting step in the conversion of ornithine to putrescine, putrescine to spermidine, and spermidine to spermine is the decarboxylation of ornithine by ornithine decarboxylase (ODC). An elevated rate of polyamine formation by stimulating ODC activity appears to be the most constant correlate of increased cell proliferation (74). Russell et al. (75) reported that the level of polyamines is significantly higher in lesional psoriasis than in uninvolved epidermis and that

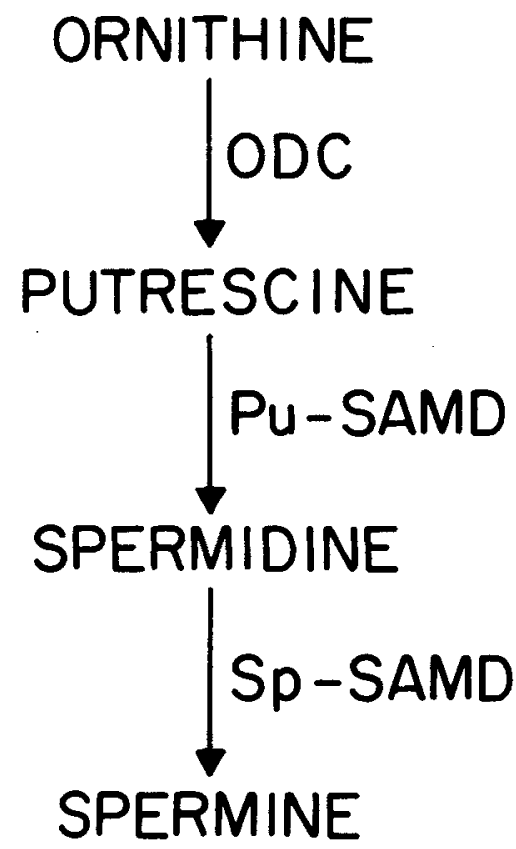

Fig. 3. Polyamine Biosynthesis in Normal and Psoriatic Human Epidermis. Abbrev: ODC, ornithine decarboxylase; Pu-SAMD, putrescine-stimulated $\mathrm{S}$ adenosyl-L-methionine decarboxylase; Sp-SAMD, spermidine-stimulated $S$-adenosyl-L-methionine decarboxylase.

the uninvolved levels are significantly higher than epidermis from normal volunteers. This increased polyamine content of uninvolved epidermis is perhaps a molecular correlate of the two-fold increase in the labelling index of uninvolved epidermis versus normal epidermis (16). Certainly the increased labelling index and polyamine content of "uninvolved" areas indicates that there is no such thing as an uninvolved area at the molecular level.

Although elevated polyamine levels have been associated with rapid proliferation for several years (74), it has been only recently that a possible cause and effect relation between polyamines and proliferation has been suggested. Mamont et al. (76) recently showed that blocking the synthesis of polyamines by an inhibitor of ODC reduced cell proliferation. 
This inhibition could be overcome by combining polyamines with the ODC inhibitor, thus bypassing the ODC blokade. Thus the inhibition of polyamine synthesis by analogs of ornithine and polyamines per se may offer new approaches to psoriasis and other proliferative diseases.

In some cells where cyclic AMP induces hypertrophy and hyperplasia, cyclic AMP induces ODC activity and polyamine formation to accompany the proliferation (77). in lesional epidermis of psoriasis the studies of Stawiski et al. $(40,41)$ indicate that cyclic AMP elevation probably inhibits cell proliferation. Since polyamines are already elevated in psoriasis the cyclic AMP rise could inhibit ODC activity in lesions of psoriasis. Such an inhibition of ODC activity has been shown by Insel and Fenno (78) in lymphoma cells where cyclic AMP also inhibits cell growth. Whether cyclic AMP inhibits ODC activity in psoriasis and in this way participates in the regulation of cell proliferation in lesions is under current study.

\section{CONCLUSION}

Today I have discussed several aspects of the molecular basis of psoriasis which we consider to be of unusual importance. I have reviewed our pragmatic approach to psoriasis research. This approach has been used because in my opinion the research tools for studying the etiology of psoriasis are not available. Until then, hopefully a dissection of the molecular systems I have described today will provide potentially better therapies.

\section{REFERENCES}

1) Watson, W., Cann, H.M., Farber, E.M. and Nall, M.L.: The Genetics of Psoriasis, Arch. Derm., 105: 197-207, 1972.

2) Marcusson, J., Möller, E. and Thyresson, N.: Penetration of HLA-linked psoriasis-predisposing gene (s): A family investigation. Acta Dermatovener (Stockholm), 56: 453-463, 1976.
3) Emmelot, P.: biochemical properties of normal and neoplastic cell surfaces; a review, Europ. J. Cancer, 9: 319-333, 1973.

4) Mahrle, G. and Orfanos, C.E.: The plasma unit membrane, Brit. J. Dermatol, 96: 215-223, 1977.

5) Whittenberger, B. and Glaser, L.: Inhibition of DNA synthesis in cultures of $3 \mathrm{~T} 3$ cells by isolated surface membranes, Proc. Natl. Acad. Sci. U.S.A., 74: 2251-2255, 1977.

6) Müller, W.E.G., Müller, I., Zahn, R.K. and Kurelec, B: Species-specific aggregation factor in sponges, Cell Tissue Kinet., 11: 23-32, 1978.

7) Baig, M.M. and Roberts, R.M.: Comparative studies on the carbohydratecontaining membrane component of normal and adenosine $3^{\prime}: 5^{\prime}$-cyclic monophosphatetreated Chinese hamster ovary cells, Biochem J., 134: 329-339, 1973.

8) Truding, R. and Morell, P.: Effect of $\mathrm{N}^{6}, \mathrm{O}^{z^{\prime}}$. dibutyryl adenosine $3^{\prime}: 5^{\prime}$-monophosphate on the release of surface proteins by murine neuroblastoma cells, J. Biol. Chem., 252: 4850-4854, 1977.

9) Cooper, R.A.: Abnormalities of cell-membrane fluidity in the pathogenesis of disease, New Eng. J. Med., 297: 371-377, 1977.

10) Schmidt, C., Penneys, N.S., Ziboh, V.A., Kiem, I. and Schlossberg, J.: Cholesterol and cholesteryl ester content in normal and pathologic scale, $J$. Invest. Derm., 68: 206-209, 1977.

11) McMichael, A.J., Morhenn, V., Payne, R., Sasazuki, T. and Farber, E.M.: HLA $C$ and $D$ antigens associated with psoriasis, Brit. J. Derm., 98: 287-292, 1978.

12) Meruelo, D. and Edidin, M.: Association of mouse liver adenosine $3^{\prime}$ : $5^{\prime}$-cyclic monophosphate (cyclic AMP) levels with histocompatibility-2genotype, Proc. Nat. Acad. Sci. U.S.A., 72: 2644-2648, 1975.

13) Puck, T.T.: Cyclic AMP, the microtubulemicrofilament system, and cancer, Proc. Nat. Acad. Sci. U.S.A., 74: 4491-4495, 1977.

14) Wanger, L. and Sundqvist, K-G.: Membraneassociated actin in psoriatic epidermis, Acta Dermatovener (Stockholm), 58: 79-82, 1978.

15) Weinstein, G.D. and Frost, P.: Abnormal cell proliferation in psoriasis, $J$. Invest. Derm., 50: 254-259, 1968.

16) Goodwin, P., Hamilton, S. and Fry, L.: A comparison between DNA synthesis and mitosis in uninvolved and involved psoriatic epidermis and normal epidermis, Brit.J. Derm., 89: 613-618, 1973.

17) Braun-Falco, O.: The Histochemistry of Psoriasis, in "Annals of The New York Academy of Sciences", Vol. 73, pp. 936-976, New York, 1958.

18) Stankler, L.: Histological findings in clinically normal palmar skin of patients with psoriasis, Brit. J. Derm., 97: 191-134, 1977. 
19) Voorhees, J.J. and Duell, E.A.: Psoriasis as a possible defect of the adenyl cyclase-cyclic AMP cascade, Arch. Derm., 104: 352-358, 1971.

20) Friedman, D.L.: Role of cyclic nucleotides in cell growth and differentiation, in Physiological Reviews, 56: $652-708,1976$.

21) Bullough, W.S. and Laurence, E.B.: Mitotic control by internal secretion: the role of the chalone-adrenalin complex, Exper. Cell Res., 39: 176-194, 1964.

22) Johnson, G.S. and Pastan, 1.: Change in growth and morphology of fibroblasts by prostaglandins, $J$. Nat. Cancer Inst., 47: 1357-1364, 1971.

23) Sutherland, E.W. and Rall, T.W.: The Relation of Adenosine $-3^{\prime}, 5^{\prime}$-phosphate and phosphorylase to the actions of catecholamines and other hormones, Pharm. Rev., 12: 265-299, 1960.

24) Voorhees, J.J., Duell, E.A., Bass, L.J., Powell, J.A. and Harrell, E.R.: Decreased cyclic AMP in the epidermis of lesions of psoriasis, Arch. Derm., 105: 695-701, 1972.

25) Voorhees, J.J., Colburn, N.H., Stawiski, M., Duell, E.A., Haddox, M. and Goldberg, N.D.: Imbalanced cyclic AMP and cyclic GMP levels in the rapidly dividing, incompletely differentiated epidermis of psoriasis, in "Control of Proliferation in Animal Celis", eds. Clarkson B and Baserga R., Cold Spring Harbor Laboratory, Cold Spring harbor, NY, pp. $635-648,1974$.

26) Härkönen, M., Hopsu-Havu, V.K. and Raij, K.: Cyclic adenosine monophosphate adenyl cyclase and cyclic nucleotide phosphodiesterase in psoriatic epidermis, Acta Dermatovener (Stockholm), 54: 13-18, 1974.

27) Yoshikawa, K., Adachi, K., Halprin, K.M. and Levine, V.: Is the cyclic AMP in psoriatic epidermis low?, Brit.J. Derm., 93: 253-258, 1975.

28) Voorhees, J.J., Duell, E.A., Stawiski, M. and Harrell. E.R.: Cyclic nucleotide metabolism in normal and proliferating epidermis, in "Advances in Cyclic Nucleotide Research, Vol. 4", eds. Greengard P and Robison GA, Raven Press, New York, pp. 117-162, 1974.

29) Yoshikawa, K., Adachi. K., Halprin, K.M. and Levine, V.: On the lack of response to catecholamine stimulation by the adenyl cyclase system in psoriatic lesions, Brit.J. Derm., 92: 619-624, 1975.

30) Aso, K., Orenberg, E.K. and Farber, E.M.: Reduced epidermal cyclic AMP accumulation following prostaglandin stimulation: its possible role in the pathophysiology of psoriasis, $J$. Invest. Derm., 65: 375-378, 1975.

31) Mahrle, G. and Orfanos, C.E.: $\beta$-Adrenerge stimulation membrangebundener adenylcyklase in normaler epidermis und mangelnde stimulierbarkeit bei psoriasis, Arch. Derm. Res., 253: 195-202, 1975.
32) Wang, Y.C., Pandey, G.N., Mendels, J. and Frazer, A.: Effect of lithium on prostaglandin $E_{1}$-stimulated adenylate cyclase activity of human platelets, Biochem. Pharm., 23: 845-855, 1974.

33) Voorhees, J.J., Marcelo, C.L. and Duell, E.A.: Cyclic AMP, cyclic GMP, and glucocorticoids as potential metabolic regulators of epidermal proliferation and differentiation, J. Invest. Derm., 65: 179-190, 1975.

34) Carter, T.N.: The relationship of lithium carbonate to psoriasis, Psychosomatics, 13: 325-327, 1972.

35) Skott, A., Mobacken, H. and Starmark, J.E.: Exacerbation of psoriasis during lithium treatment, Brit.J. Derm., 96: 445-448, 1977.

36) Sфndergaard, J., Wadskov, S., Jensen, H.A. and Mikkelsen, H.I.: Aggravation of psoriasis and occurrence of psoriasiform cutaneous eruptions induced by practolol (Eraldin), Acta Dermatovener (Stockholm), 56: 239-243, 1976.

37) Wiley, H. and Weinstein, G.: Selective proliferative abnormality induced by propranolol in uninvolved psoriatic skin compared to normal skin, J. Invest. Derm., 68: 239, 1977

38) Vassalli, J.D., Hamilton, J. and Reich, E.: Macrophage plasminogen activator: modulation of enzyme production by anti-inflammatory steroids, mitotic inhibitors, and cyclic nucleotides, Cell, 8: 271-281, 1976.

39) Fraki, J.E. and Hopsu-Havu, V.K.: Plasminogen activator and histone hydrolyzing proteases in psoriasis scales - possible role in increased cell division, Annals of Clin. Res., 8: 335-339, 1976.

40) Stawiski, M.A., Powell, J.A., Lang, P.G., Schork, A., Duell, E.A. and Voorhees, J.J.: Papaverine: its effects on cyclic AMP in vitro and psoriasis in vivo, $J$. Invest. Derm, 64: 124-127, 1975.

41) Stawiski, M.A., Rusin, L., Schork, M.A., Burns, T., Duell, E.A. and Voorhees, J.J.: Ro 20-1724 elevates epidermal cyclic AMP levels in vitro and improves psoriasis in vivo, Clin. Res., 24: 267, 1976.

42) Halprin, K.M., Adachi, K., Yoshikawa, K., Levine, V., Mui, M.M. and Hsia, S.L.: Cyclic AMP and psoriasis, J. Invest. Derm., 65: 170-178, 1975.

43) Delescluse, C., Colburn, N.H., Duell, E.A. and Voorhees, J.J.: Cyclic AMP-elevating agents inhibit proliferation of keratinizing guinea pig epidermal cells, Differentiation, 2: 343-350, 1974.

44) Flaxman, B.A. and Harper, R.A.: In vitro analysis of the control of keratinocyte proliferation in human epidermis by physiologic and pharmacologic agents, $J$. Invest. Derm., 65: 52-59, 1975.

45) Delescluse, C., Fukuyama, K: and Epstein, W.L.: Dibutyryl cyclic AMP-induced differentiation of epidermal cells in tissue culture, J. Invest. Derm., 66: 8-13, 1976.

46) Chopra, D.P.: Effects of theophylline and dibutyryl 
cyclic AMP on proliferation and keratinization of human keratinocytes, Brit. J. Derm., 96: 255-262, 1977

47) Posternak, F., Posternak, Th., Orusco, M., Cehovic, G. and Laugier, P.: Essais de traitement du psoriasis par injections intra-lésionnelles d'AMPc, de dibutyryl8-thio AMPc, et de théophylline, Journées Nationales de Dermatologie, 103: 640-644, 1976.

48) Anonymous: Cyclic AMP and Dibutyryl AMP in Treatment of Psoriasis, Chinese Med.J., 2: 141-146, 1976.

49) Iizuka, H., Adachi, K., Halprin, K.M. and Levine, V.: Cyclic AMP accumulation in psoriatic skin: Differential responses to histamine, AMP, and epinephrine by the uninvolved and involved epidermis, $J$. Invest. Derm., 70: 250-253, 1978.

50) Newcombe, D.S., Ciosek, C.P. Jr., Ishikawa, Y. and Fahey, J.V.: Human synoviocytes: Activation and desensitization by prostaglandins and 1-epinephrine, Proc. Nat. acad. Sci. U.S.A., 72: 3124-3128, 1975.

51) Simantov, R. and Sachs, L.: Differentiation desensitization of functional adrenergic receptors in normal and malignant myeloid cells: Relationship to receptor. mediated hormone cytotoxicity, Proc. Natl. Acad. Sci. U.S.A., 75: 1805-1809, 1978.

52) Robin. E.D.: Claude Bernard's (extended) milieu interieur revisited: autoregulation of cell and subcell integrity, Clin. Sci. \& Molecular Med., 52: 443-448, 1977.

53) Marcelo, C.L., Kim, Y.G., Kaine, J. and Voorhees, J.J.: Stratification, specialization and proliferation of primary keratinocyte cultures: Evidence of a functioning in vitro epidermal cell system, J. Cell Biology, Submitted for publication, 1978.

54) Marcelo, C.L. and Duell, E.A.: Cyclic AMP stimulation of keratinocyte proliferation is suppressed by glucocorticoids, J. Invest. Derm., 70: 211, 1978.

55) Hadden, J.W., Hadden, E.M., Haddox, M.K. and Goldberg, N.D.: Guanosine 3': $5^{\prime}$-cyclic monophosphate: A possible intracellular mediator of mitogenic influences in lymphocytes, Proc. Nat. Acad. Sci. U.S.A., 69: 3024-3027, 1972.

56) Goldberg, N.D. and Haddox, M.K.: Cyclic GMP metabolism and involvement in biological regulation, in "Annual Review of Biochemistry, Vol. 46", Annual Reviews, Inc., Palo Alto, Ca., pp. 823-896, 1977.

57) Nesbitt, J.A. III, Anderson, W.B., Miller, Z., Pastan, I., Russell, T.R. and Gospodarowicz, D.: Guanylate cyclase and cyclic guanosine $3^{\prime}$ : $5^{\prime}$-monophosphate phosphodiesterase activities and cyclic guanosine $3^{\prime}$ : $5^{\prime}$-monophosphate levels in normal and transformed fibroblasts in culture, $J$, Biol. Chem., 251: 2344-2352, 1976

58) Voorhees, J.J., Stawiski, M., Duell, E.A., Haddox, M.K. and Goldberg, N.D.: Increased cyclic GMP and decreased cyclic AMP levels in the hyperplastic abnormally differentiated epidermis of psoriasis, Life Sci., 13: 639-653, 1973.

59) Marcelo, C.L., Duell, E.A., Stawiski, M.A., An derson, T.F. and Voorhees, J.J.: Cyclic nucleotide levels in psoriatic and normal epidermis, $J$. Invest. Derm., January, 1979.

60) Ramwell, P.W., E.M.K. and Sintetos, A.L.: Regulation of the arachidonic acid cascade, Biol. Reprod., 16: 70-87, 1977.

61) Voorhees, J.J., Duell, E.A., Anderson, T.F., Stawiski, M.A., Hammarström, S. and Hamberg, M.: Pharmacological effects of glucocorticoid on arachidonic acid content of lesions of psoriasis, in "Advances in Prostaglandin and Thromboxane Research, Vol. 3", eds. Galli C, Samuelsson B and Paoletti R, Raven Press, new York, pp. 175-181, 1978.

62) Hammarström, S., Hamberg, M., Samuelsson, B., Duell, E.A., Stawiski, M. and Voorhees, J.J.: Increased concentrations of nonesterified arachidonic acid, 12L-hydroxy-5, 8, 10, 14-eicosatetraenoic acid, prostaglandin $\mathrm{E}_{2}$ and prostaglandin $\mathrm{F}_{2 \alpha}$ in epidermis of psoriasis, Proc. Nat. Acad. Sci. U.S.A., 72: 5130-5134, 1975.

63) Penneys, N.S.: Ziboh, V., Lord, J. and Simon, P.: Inhibitor(s) of prostaglandin synthesis in psoriatic plaque, Nature, 254: 351-352, 1975.

64) Turner, S.R., Tainer, J.A. and Lynn, W.S.: Biogenesis of chemotactic molecules by the arachidonate lipoxygenase system of platelets, Nature, 257: 680-681, 1975.

65) Goetzl, E.J., Woods, J.M. and Gorman, R.R.: Stimulation of human eosinophil and neutrophil polymorphonuclear leukocyte chemotaxis and ran dom migration by 12L-hydroxy-5, 8, 10, 14 eicosatetraenoic acid, J. Clin. Invest., 59: 179-183, 1977.

66) Penneys, N.S., Simon, P., Ziboh, V.A. and Schlossberg, J.: In vivo chemotaxis induced by polyunsaturated fatty acids, $J$. Invest. Derm., 69: 435-438, 1977.

67) Wallach, D. and Pastan, I.: Stimulation of guanylate cyclase of fibroblasts by free fatty acids, $J$. Biol. Chem., 251: 5802-5809, 1976.

68) Hidaka, H. and Asano, T.: Stimulation of human platelet guanylate cyclase by unsaturated fatty acid peroxides, Proc. Natl. Acad. Sci. U.S.A., 74: 3657-3661, 1977.

69) Anderson, W.B. and Jaworski, C.J.: Modulation of adenylate cyclase activity of fibroblasts by free fatty acids and phospholipids, Arch. Biochem. Biophys., 180: 374-383, 1977

70) Shier, W.T., Baldwin, J.H., Nilsen-Hamilton, M., Hamilton, R.T. and Thanassi, N.M.: Regulation of guanylate and adenylate cyclase activities by 
lysolecithin, Proc. Natl. Acad. Sci. U.S.A., 73 1586-1590, 1976.

71) Shier, W.T.: Inhibition of prostaglandin synthesis by lysolecithin, Biochem. Biophys. Res. Comm., 78: 1168-1174, 1977.

72) Lapetina, E.G., Schmitges, C.J., Chandrabose, K. and Cuatrecasas, P.: Cyclic adenosine $3^{\prime}, 5^{\prime}$. monophosphate and prostacyclin inhibit membrane phospholipase activity in platelets, Biochem. Biophys. Res. Comm., 76: 828-835, 1977.

73) Minkes, M., Stanford, N., Chi, M.M., Roth G.J., Raz, A., Needleman, P. and majerus, P.W.: Cyclic adenosine $3^{\prime}, 5^{\prime}$-monophosphate inhibits the avail. ability of arachidonate to prostaglandin synthetase in human platelet suspensions, J. Clin. Invest., 59: 449-454, 1977.

74) Fillingame, R.H., Jorstad, C.M. and Morris, D.R.: Increased cellular levels of spermidine or spermine are required for optimal DNA synthesis in lymphocytes activated by concanavalin A, Proc. Nat. Acad. Sci. U.S.A., 72: 4042-4045, 1975.
75) Russell, D.H., Combest, W.L., Duell, E.A., Stawiski, M.A., Anderson, T.F. and Voorhees, J.J.: Glucocorticoid inhibits elevated polyamine biosynthesis in psoriasis, J. Invest. Derm., 71: 177-181, 1978.

76) Mamont, P.S., Böhlen, P., McCann, P.P., Bey, P., Schuber, F. and Tardif, C.: $\alpha$-methyl ornithine, a potent competitive inhibitor of ornithine decarboxylase, blocks proliferation of rat hepatoma cells in culture, Proc. Natl. Acad. Sci. U.S.A., 73: 1626-1630, 1976.

77) Russell, D.H. and Stambrook, P.J.: Cell cycle specific fluctuations in adenosine $3^{\prime}: 5^{\prime}$-cyclic monophosphate and polyamines of Chinese hamster cells, Proc. Nat. Acad. Sci. U.S.A., 72: 1482-1486, 1975.

78) Insel, P.A. and Fenno, J.: Cyclic AMP-dependent protein kinase mediates a cyclic AMP-stimulated decrease in ornithine and $\mathrm{S}$-adenosylmethionine decarboxylase activities, Proc. Natl. Acad. Sci. U.S.A., 75: 862-865, 1978. 